\title{
Perencanaan lanskap daya tarik wisata sejarah eks Pelabuhan Buleleng
}

\author{
Kadek Agus Arya Wibawa ${ }^{1}$, Lury Sevita Yusiana ${ }^{1 *}$, I Putu Sudana² \\ 1. Prodi Arsitektur Pertamanan, Fakultas Pertanian, Universitas Udayana, Jl. P.B. Sudirman, Denpasar, \\ Indonesia \\ 2. Prodi Industri Perjalanan Wisata, Fakultas Pariwisata, Universitas Udayana, Jl. P.B. Sudirman, \\ Denpasar, Indonesia
}

*E-mail: lury.yusiana@unud.ac.id

\begin{abstract}
Planning of Attractive History at Ex Buleleng Port. The city of Singaraja was once the capital city of Soenda Ketjil until 1958. Several supporting infrastructures for the capital city were built, one of which was a port called Pelabuhan Buleleng which was the main port to the Province of Bali. The transfer of the capital and the main port of Bali Province became the beginning of the decline of the function of the Port of Buleleng so that it needs to be carried out planning the landscape of the historical tourism attraction of the Ex-Port of Buleleng. The purpose of this study was to analyze the site related to the potential and constraints in tourism development and determine appropriate planning in the effort to arrange the Ex-Buleleng Port as a historical tourist attraction in Singaraja City. The method used is the survey method. The stages of this research are preparation of inventory, analysis, synthesis, and design. The method of data collection is done through field observations, interviews with speakers, literature studies, and distributing questionnaires (communities and visitors). The results of this study show the potential of historical value on the site that can be used as a historical tourist attraction, while the problems encountered include problems of circulation, cleanliness, structuring, and other supporting facilities. The planning concept produced in this study is educative and recreational historical tourism that is able to support the preservation of historical resources on the site by making the Ex-Buleleng Port as a historical and cultural information center and recreation in the Buleleng Regency. Suggestions that can be given are recommendations on the concept of tourist space, accessibility and circulation, tourist facilities, the concept of vegetation and tourism activities
\end{abstract}

Keywords: Education and Recreation, Ex Buleleng Port, Historical Value, Landscape Planning

\section{Pendahuluan}

Kabupaten Buleleng merupakan kabupaten yang terletak di Bali Utara dengan Ibukotanya Singaraja. Kota Singaraja pernah menjadi Ibu Kota Soenda Ketjil hingga tahun 1958. Beberapa infrastuktur penunjang ibu kota pun dibangun, salah satunya adalah pelabuhan yang bernama Pelabuhan Buleleng yang merupakan pelabuhan utama menuju Provinsi Bali. Perpindahan ibukota dan pelabuhan utama Provinsi Bali ini ke Kota Denpasar menjadi awal menurunnya fungsi Pelabuhan Buleleng, hingga kondisi bangunannya banyak yang mengalami kerusakan dan pelapukan. Kondisi terburuk terjadi akibat pengembangan kawasan yang berujung pada pembongkaran bangunan pergudangan yang merupakan bangunan tua bersejarah di kawasan ini yang dialihfungsikan menjadi gedung pertemuan yang memiliki gaya arsitektur yang sangat berbeda dengan karakter sejarah yang ada. Oleh karena itu perlunya perencanaan Eks Pelabuhan Buleleng sebagai daya tarik wisata sejarah perlu dilakukan untuk melestarikan Eks Pelabuhan Buleleng sebagai salah satu pelabuhan colonial di Bali. Tujuan dari penelitian ini adalah untuk mengetahui potensi dan kendala yang terdapat pada kawasan Eks Pelabuhan Buleleng dan menentukan konsep perencanaan yang sesuai dalam upaya penataan kawasan Eks Pelabuhan Buleleng sebagai daya tarik wisata sejarah di Kota Singaraja, Bali.

\section{Metode}

Metode yang digunakan adalah metode survei. Tahapan dari penelitian ini yaitu persiapan inventarisasi, analisis, sintesis, dan perancangan. Teknik pengumpulan data dilakukan melalui observasi lapang, wawancara dengan narasumber, studi pustaka, serta penyebaran kuesioner (masyarakat dan pengunjung). 
3. Hasil dan Pembahasan

3.1 Kondisi Umum

Sesuai dengan sertipikat tanah No: 22.04.05.12.1.00010 dan sertipikat tanah No: 22.04.05.12.1.00010 dari Badan Pertanahan Nasional luas areal Eks Pelabuhan Buleleng adalah $10.530 \mathrm{~m}^{2}$. Batasan tapak yaitu: Sebelah Utara: Laut Bali, Sebelah Selatan: Pertokoan, Sebelah Timur: Pura Segara Buleleng, Sebelah barat: Singaraja Square

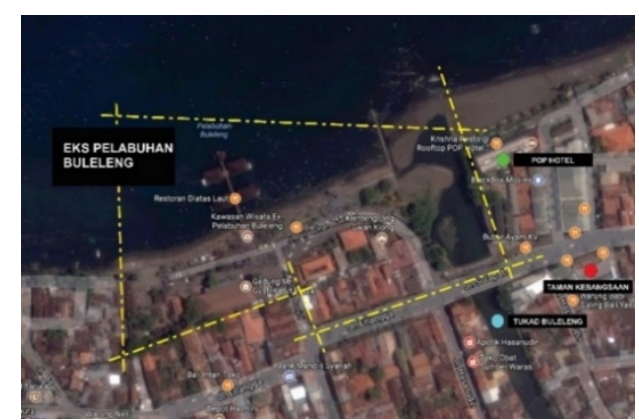

Gambar 1. Peta lokasi daya tarik wisata Eks Pelabuhan Buleleng

(Sumber: https://www.google.co.id/maps, 2017)

\subsection{Inventarisasi}

\subsubsection{Sejarah Eks Pelabuhan Buleleng}

Sejarah Eks Pelabuhan Buleleng dibagi menjadi dua periode yaitu zaman kekuasaan Hindia Belanda dan Pasca kemerdekaan. Zaman kekuasaan Hindia Belanda ditandai dengan dijadikannya Pelabuhan Buleleng sebagai pintu gerbang utama Pulau Bali dan jembatan emas persinggahan menuju kepulauan di sebelah timur Indonesia, terutama menyangkut urusan monopoli perdagangan. Sedangkan Pasca kemerdekaan ditandai dengan dibangunnya monumen Yudha Mandala Tama pada tahun 1987 sebagai monumen peringatan perjuangan pemuda Buleleng melawan Belanda.

\subsubsection{Bangunan Eksisting}

Bangunan eksisting tapak yang dapat diidentifikasi antara lain: Jembatan Kolonial, tugu I Ketut Merta, Klenteng Ling Gwan Kiong, Museum Soenda Ketjil, gedung Pengelola Unit Pelaksana Teknis (UPT) Eks Pelabuhan Buleleng, wantilan, gedung I Gusti Ketut Pudja, Pura Segara Buleleng, Eks Dermaga Pelabuhan Buleleng, Monumen Yudha Mandala Tama.

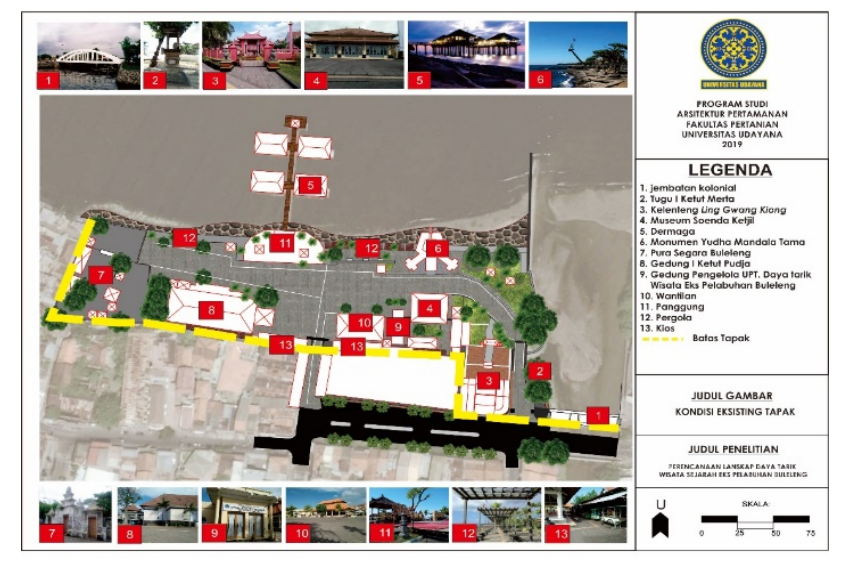

Gambar 2. Bangunan eksisiting tapak

\subsection{Analisis dan Sintesis \\ 3.3.1 Analisis Fisik dan Biofisik \\ 3.3.1.1 Tata guna lahan}


Tata guna lahan Eks Pelabuhan Buleleng terhadap wilayah Kota Singaraja sudah sesuai dengan aturan RTRW tahun 2013 yang masih berlaku hingga kini. Eks Pelabuhan Buleleng merupakan kawasan strategis di Kabupaten Buleleng karena potensinya menjadi daya tarik wisata khususnya wisata sejarah. Selain nilai sejarah yang menjadi karakter dari tapak, Eks Pelabuhan Buleleng juga memiliki nilai signifikansi budaya yang cukup penting bagi Kota Singaraja.

\subsubsection{Iklim}

Secara umum seluruh Kabupaten/ Kota yang berada di wilayah Indonesia, termasuk Kabupaten Buleleng memiliki dua musim yaitu musim hujan dan kemarau. Curah hujan tertinggi berada pada bulan Januari dengan rata-rata curah hujan $326,54 \mathrm{~mm}$ dan terendah pada bulan Agustus dengan rata-rata curah hujan 4,05 mm (Badan Meteorologi, Klimatologi, dan Geofisika (BMKG) Wilayah III Denpasar, 2018).

\subsubsection{Hidrologi dan tanah}

Jenis saluran drainase yang berada di kawasan ini termasuk ke dalam jenis drainase terbuka. Saluran drainase tersebut merupakan drainase buatan yang dibuat untuk mengalirkan air dari tapak maupun dari jalan raya menuju ke laut maupun Tukad Buleleng.

Bila ditinjau secara geologis, wilayah Eks Pelabuhan Buleleng yang berada di Kelurahan Kampung Bugis tersusun atas batuan hasil letusan gunung berapi yang terjadi pada masa yang berlainan. Batuan tersebut pada umumnya terdiri atas breksi, lava, dan tufa, kecuali sepanjang pantai utara yang tersusun dari endapan aluvial, sedangkan jenis tanah pada wilayah ini adalah tanah regosol dengan tekstur yang sebagian besar dalam kategori tekstur sedang (BPS Kabupaten Buleleng, 2011).

\subsubsection{Vegetasi}

Vegetasi eksisting di area Eks Pelabuhan Buleleng terdiri dari beberapa strata tanaman seperti pohon sedang, perdu, semak dan groundcover. Keberadaan vegetasi pada tapak kurang diketahui hubungannya dengan sejarah Eks Pelabuhan Buleleng. Dilihat dari jenis vegetasi yang terdapat pada tapak sangat kurang dalam penataan dan umumnya bukan merupakan tanaman yang memiliki nilai sejarah.

\subsubsection{Visual}

Secara umum kondisi visual yang ada pada tapak didominasi oleh bangunan-bangunan tua yang tergolong menghadap ke dalam tapak. Kondisi visual Eks Pelabuhan Buleleng yang tergolong bad view terlihat pada tumpukan sampah, pembuangan limbah dari restoran apung pada dermaga, sudut-sudut gedung yang kotor dan tidak terawat serta vegetasi yang tumbuh tidak terawat di sekitarnya. Selain itu keberadaan elemen penyusun tapak terlihat tidak memiliki kesatuan. Kondisi ini dapat menurunkan kualitas visual pada tapak.

Good view pada tapak terlihat dari keunikan arsitektur bangunan yang bergaya Hindia Belanda (indis) dan view laut lepas dengan keindahan sunrise dan sunset-nya. Hal ini dapat dimanfaatkan sebagai daya tarik tapak. Pada bagian luar daya tarik wisata Eks Pelabuhan Buleleng sudah didominasi oleh pertokoan dan juga area tidak terawat yang dijadikan tempat berjualan bagi pedagang kaki lima. Oleh karena itu untuk pengembangan daya tarik wisata Eks Pelabuhan Buleleng perlu dilakukan penataan pada elemen pembentuk lanskap dan bagian luar tapak sesuai dengan karakter tapak sebagai sebuah pelabuhan kolonial.

\subsubsection{Analisis kesejarahan}

Berdasarkan hasil observasi di yang telah dilakukan terhadap lanskap sejarah Eks Pelabuhan Buleleng maka dilakukan penilaian lanskap sejarah Eks Pelabuhan Buleleng. Penilaian ini dilakukan dengan analisis signifikansi lanskap sejarah. Analisis ini menggunakan penilaian menurut Harris dan Dines (1988) yaitu penilaian keaslian (originality) pada Tabel 3 dan keunikan (uniqueness) pada Tabel 4.

\section{Tabel 1. Penilaian keaslian}

\begin{tabular}{clcccccc}
\hline \multirow{2}{*}{ No Unit Lanskap Sejarah } & \multicolumn{1}{c}{ Komponen Penilaian } \\
& & A & B & C & D & Total & Kategori \\
\hline 1 & Jembatan Kolonial & 3 & 3 & 3 & 2 & 11 & Tinggi \\
2 & Tugu I Ketut Merta & 2 & 2 & 1 & 2 & 7 & Sedang \\
3 & Klenteng Ling Gwan Kiong & 2 & 2 & 2 & 3 & 9 & Tinggi \\
4 & Museum Soenda Ketjil & 2 & 2 & 2 & 2 & 8 & Sedang \\
5 & Monumen Yudha Mandala Tama & 2 & 2 & 2 & 2 & 8 & Sedang \\
6 & Eks Dermaga Pelabuhan Buleleng & 2 & 2 & 2 & 1 & 7 & Sedang \\
7 & Gedung I Gusti Ketut Pudja & 1 & 1 & 1 & 1 & 4 & Rendah \\
8 & Pura Segara Buleleng & 2 & 2 & 2 & 3 & 9 & Tinggi \\
\hline
\end{tabular}

A. Penggunaan lahan, B. Elemen/ Objek Lanskap, C. Karakter/Gaya, D. Aksesibilitas/ Sirkulasi

(Keterangan: Rendah: $3 \leq n \leq 6$; Sedang: $7 \leq n \leq 9$; Tinggi: $10 \leq n \leq 12$ ) 
Berdasarkan hasil penilaian keaslian dapat dilihat bahwa terdapat tiga unit lanskap yang memiliki nilai keaslian tinggi. Unit-unit lanskap tersebut adalah Jembatan Kolonial, Klenteng Ling Gwang Kiong dan Pura Segara Buleleng. Ketiga unit lanskap tersebut merupakan unit yang memang sudah ada mulai dari zaman kerajaan hingga zaman kolonial. Perubahan gaya arsitekturnya masih tetap sama seperti dulu hanya saja untuk pemeliharaan dilakukan beberapa perubahan kecil seperti memoles bagian yang rapuh serta cat ulang namun tidak meninggalkan gaya arsitektur lamanya.

Gedung I Gusti Ketut Pudja memiliki nilai paling rendah karena sangat berbeda dengan kondisi sekitar tapak yang bernuansa kolonial. Gedung ini terlihat lebih megah dengan gaya modern.

Tabel 2. Penilaian keunikan

\begin{tabular}{llcccccc}
\hline \multicolumn{1}{c}{ Unit Lanskap Sejarah } & \multicolumn{5}{c}{ Komponen Penilaian } \\
& & A & B & C & D & Total & Kategori \\
\hline 1 & Jembatan Kolonial & 3 & 3 & 3 & 3 & 12 & Tinggi \\
2 & Tugu I Ketut Merta & 2 & 2 & 1 & 1 & 6 & Rendah \\
3 & Klenteng Ling Gwan Kiong & 3 & 3 & 2 & 2 & 10 & Tinggi \\
4 & Museum Soenda Ketjil & 3 & 3 & 3 & 2 & 11 & Tinggi \\
5 & Monumen Yudha Mandala Tama & 3 & 2 & 3 & 2 & 10 & Tinggi \\
6 & Eks Dermaga Pelabuhan Buleleng & 2 & 2 & 2 & 1 & 7 & Sedang \\
7 & Gedung I Gusti Ketut Pudja & 1 & 1 & 1 & 1 & 4 & Rendah \\
8 & Pura Segara Buleleng & 3 & 2 & 3 & 3 & 11 & Tinggi \\
\hline
\end{tabular}

\section{(A. Asosiasi Kesejarahan, B. Integritas, C. Kelangkaan, D. Kualitas Estetika)} Keterangan: Rendah: $3 \leq n \leq 6$; Sedang: $7 \leq n \leq 9$; Tinggi: $10 \leq n \leq 12$

Berdasarkan penilaian keunikan yang telah dilakukan jembatan kolonial memiliki nilai paling tinggi. Jembatan Kolonial Belanda memiliki keharmonisan tinggi dengan lingkungan sekitarnya. Kekhasan bangunan yang terletak pada bentuk, konstruksi jembatan yang masih dipertahankan hingga sekarang. Karena ciri khasnya Jembatan Kolonial Belanda dapat dijadikan sebagai landmark di kawasan Eks Pelabuhan Buleleng.

Gedung I Gusti Ketut Pudja memiliki nilai paling rendah karena sangat berbeda dengan kondisi sekitar tapak yang bernuansa kolonial. Gedung ini terlihat lebih megah dengan gaya modern.

\subsubsection{Analisis daya tarik wisata}

\subsubsection{Atraksi wisata}

Eks Pelabuhan Buleleng menyimpan banyak bangunan-bangunan yang memiliki nilai signifikansi budaya, sehingga pengelola harus berupaya melakukan pelestarian terhadap bangunan bersejarah tersebut. Beberapa bangunan yang dipreservasi di lokasi Eks Pelabuhan Buleleng diantaranya:

a. Jembatan Kolonial Belanda

Jembatan Kolonial Belanda ini memiliki kekhasan bangunan yang terletak pada bentuk, konstruksi jembatan dan menjadi landmark di kawasan Eks Pelabuhan Buleleng. Jembatan ini kini difungsikan hanya untuk pejalan kaki. Terdapat beberapa coretan pada jembatan dan cat jembatan yang mengelupas membuat bad view pada Jembatan Kolonial Belanda ini. Kondisi ini diperburuk dengan keadaan Tukad Buleleng yang berada dibawah jembatan yang sering membawa sampah dan menimbulkan bau tidak sedap.

b. Tugu I Ketut Merta

Tugu ini terletak tepat diareal pintu masuk Eks Pelabuhan Buleleng. Tujuan dibangunnya tugu ini adalah untuk mengenang kisah heroik perjuangan I Ketut Merta. Kurangnya papan intepretasi dan lokasi tugu yang agak ke dalam membuat tugu ini tidak banyak dikunjungi wisatawan. Kondisi tugu yang kurang terawat juga menyebabkan bad view sehingga tujan utama pembangunan tugu tidak sampai ke pengunjung. Penambahan papan intepretasi sangat diperlukan guna memberikan informasi kepada pengunjung tentang nilai historis yang terkandung pada monumen.

c. Klenteng Ling Gwan Kiong

Klenteng Ling Gwan Kiong memiliki bentuk dan tampilan bangunan yang sangat unik. Keunikan dari klenteng ini dikarenakan bentuk dan tampilan klenteng yang oriental dan ditambah dengan warna khas oriental (Klenteng pada umumnya), yaitu kombinasi merah menyala dengan jingga, kuning, dan gradasinya.

d. Museum Soenda Ketjil

Museum Soenda Ketjil ini dikelola oleh Dinas Kebudayaan Kabupaten Buleleng. Museum ini berisikan informasi mengenai Kota Singaraja yang pernah menjadi Ibukota Provinsi Soenda Ketjil di masa lalu. 
Provinsi yang mewilayahi Bali, NTB, NTT sebelum akhirnya ketiga daerah ini menjadi dareah otonomi tersendiri. Sejarah masa lalu tentang Soenda Ketjil digambarkan melalui museum Soenda Ketjil yang diresmikan pada tanggal 13 Maret 2018. Bangunan museum ini merupakan satu satunya bangunan bekas kantor peninggalan pemerintahan belanda yang masih bertahan. Keterbatasan informasi, ragam bahasa (karna dominan berbahasa Indonesia), pelayanan, aktifitas dan fasilitas pada museum membuat suasana pada museum menjadi kurang menarik. Oleh karena itu perlu rencana pengembangan atraksi dan fasilitas untuk menarik wisatawan.

e. $\quad$ Eks Dermaga Pelabuhan Buleleng

Eks Dermaga Pelabuhan Buleleng ini merupakan salah satu daya tarik yang banyak dikunjungi karena view laut lepas dan pemandangan sunset dan sunrise-nya yang indah. Tempat ini juga ramai dikunjungi oleh masyarakat lokal untuk memancing. Pada beberapa kondisi tertentu, wisatawan yang datang ke Buleleng dengan menggunakan yacht akan melabuh dan masuk ke Eks Pelabuhan Buleleng melalui dermaga ini.

Kondisi dermaga dengan restoran didalamnya menyebabkan pandangan dari arah pelabuhan menjadi terhalang. Pembuangan limbah restoran ke laut membuat dermaga ini menjadi kumuh sehingga menghasilkan bad view. Selain bad view keberadaan restoran ini dapat mengubah karakteristik tapak sebagai sebuah dermaga Pelabuhan Buleleng. Pengemballian fungsi dermaga dengan penrencanaan atraksi wisata pada dermaga dapat dijadikan salah satu solusi untuk memperkuat karakter tapak sebagai sebuah pelabuhan kolonial.

f. Monumen Yudha Mandala Tama

Monumen ini diresmikan pada tahun 1987 bertujuan untuk mengenang peristiwa perobekan bendera Belanda oleh I ketut Merta pada tanggal 27 Oktober 1945 silam saat pertempuran besar Belanda dan pemuda Buleleng terjadi.

g. Gedung I Gusti Ketut Pudja

Gedung I Gusti Ketut Pudja dulunya merupkan bekas bangunan pergudangan dengan gaya arsitektur Indis yang menjadi identitas Pelabuhan Kolonial pada masanya. Pemanfaatan gedung juga kurang dimanfaatkan dengan maksimal. Oleh karena itu perlu dilakukan perencanaan aktivitas wisata guna memaksimalkan fungsi gedung ini.

h. Pura Segara Buleleng

Ciri khas pura segara ini adalah gaya arsitektur kori Pura Segara dengan kolaborasi arsitektur bali dan gaya Indis yang masih dipertahankan dari zaman dulu hingga sekarang.

\subsubsection{Analisis Daya Tarik Wisata}

Berdasarkan hasil observasi di yang telah dilakukan terhadap lanskap sejarah Eks Pelabuhan Buleleng maka dilakukan penilaian lanskap sejarah Eks Pelabuhan Buleleng. Penilaian nilai daya tarik wisata merupakan penilaian yang digunakan untuk mengevaluasi faktor internal dari daya tarik wisata itu sendiri. Penilaian daya Tarik wisata diadaptasi dari Harris and Dinnes, 1988 dalam Arie, 2013 modifikasi. Adapun yang dinilai meliputi kualitas daya tarik wisata, kondisi daya tarik wisata, dukungan pengembangan daya tarik wisata, aksesibilitas, dan fasilitas penunjang daya tarik wisata (Tabel 5).

Tabel 3. Penilaian daya tarik wisata

\begin{tabular}{|c|c|c|c|c|c|c|c|c|c|c|c|c|}
\hline \multirow{3}{*}{ No } & \multirow{3}{*}{ Unit Lanskap Sejarah } & \multicolumn{11}{|c|}{ Komponen Penilaian } \\
\hline & & \multicolumn{4}{|c|}{ I } & \multicolumn{3}{|c|}{ II } & \multicolumn{2}{|c|}{ III } & \multirow{2}{*}{ Total } & \multirow{2}{*}{ Kategori } \\
\hline & & A & $\mathrm{B}$ & $\mathrm{C}$ & D & $\mathrm{E}$ & $\mathrm{F}$ & G & $\mathrm{H}$ & I & & \\
\hline 1 & Jembatan Kolonial & 3 & 3 & 2 & 1 & 2 & 2 & 2 & 3 & 3 & 21 & Tinggi \\
\hline 2 & Tugu I Ketut Merta & 1 & 1 & 1 & 1 & 2 & 2 & 2 & 3 & 3 & 16 & Sedang \\
\hline 3 & Klenteng Ling Gwan Kiong & 3 & 3 & 1 & 1 & 2 & 2 & 2 & 3 & 3 & 20 & Sedang \\
\hline 4 & Museum Soenda Ketjil & 3 & 3 & 3 & 1 & 2 & 3 & 2 & 3 & 3 & 22 & Tinggi \\
\hline 5 & Monumen Yudha Mandala Tama & 2 & 2 & 1 & 1 & 2 & 2 & 2 & 3 & 3 & 18 & Sedang \\
\hline 6 & Eks Dermaga Pelabuhan Buleleng & 3 & 3 & 2 & 2 & 2 & 2 & 2 & 3 & 3 & 22 & Tinggi \\
\hline 7 & Gedung I Gusti Ketut Pudja & 1 & 1 & 1 & 1 & 1 & 1 & 1 & 1 & 1 & 9 & Rendah \\
\hline 8 & Pura Segara Buleleng & 1 & 1 & 3 & 1 & 1 & 2 & 2 & 3 & 3 & 17 & Sedang \\
\hline
\end{tabular}

(Keterangan: Rendah: $9 \leq n \leq 15 ;$ Sedang: $16 \leq n \leq 20$; Tinggi: $21 \leq n \leq 27$

I: kualitas daya tarik wisata, II: kondisi daya tarik wisata, III: dukungan pengembangan daya tarik wisata 
A: atraksi wisata, B: kekuatan atraksi wisata, C: kegiatan wisata, D: keragaman atraksi/ daya tarik wisata, E: Kondisi fisik daya tarik wisata secara langsung, F: kebersihan lingkungan DTW, G: keindahan lingkungan DTW, H: pengembangan dan promosi DTW, I: media promosi DTW)

Secara keseluruhan elemen penyusun lanskap daya tarik wisata Eks Pelabuhan Buleleng sudah terpublikasi baik di meda cetak maupun elektronik yang dikelola langsung oleh Dinas Pariwisata Kabupaten Buleleng guna memajukan kualitas pariwisata buleleng (Agus, wawancara 17-05-2018).

Gedung I Gusti Ketut Pudja memiliki nilai paling rendah dikarenakan karena merupakan Gedung modern yang jarang dipergunakan untuk kepentingan wisata namun masih dapat di manfaatkan untuk menunjang pariwisata.

\subsubsection{Aksesibilitas dan Sirkulasi}

a. Aksesibilitas

Aksesibilitas menuju tapak terbilang sangat mudah karena berada dipinggir jalan raya. Kondisi jalan yang ditempuh untuk menuju ke daya tarik wisata Eks Pelabuhan Buleleng cukup baik dengan topografi jalan yang relatif datar. Terminal terdekat menuju daya tarik wisata Eks Pelabuhan Buleleng tidak terlalu jauh. Adapun terminal terdekat yaitu Terminal Penarukan dan Terminal Banyuasri.

a. Sirkulasi

Akses untuk masuk daya tarik wisata Eks Pelabuhan Buleleng berupa dua gerbang yang berada di sebelah timur dan barat. Gerbang timur dan barat memiliki ukuran cukup besar dengan material beton dan jalan masuk berupa material paving. Ukuran dari lebar gerbang sekitar $5 \mathrm{~m}$, namun hanya gerbang timur yang difungsikan untuk keluar-masuk area Eks Pelabuhan Buleleng sedangkan gerbang barat ditutup menggunakan portal. Dalam area Eks Pelabuhan Buleleng tidak terlihat adanya sirkulasi yang cukup jelas, setiap bangunan yang ada hanya dihubungkan oleh area terbuka yang ditutupi oleh paving.

\subsubsection{Fasilitas pendukung}

Beberapa fasilitas pendukung yang terdapat pada eks pelabuhan buleleng, diantaranya: Penanda (penanda lokasi evakuasi tsunami, larangan, dan peraturan daerah), Toilet, Layanan informasi, dan Tempat parkir. Saat ini Eks Pelabuhan Buleleng di kelola oleh Unit Pelaksana Teknis (UPT) Pengelola Eks Pelabuhan Buleleng yang berada dibawah Dinas Pariwisata Kabupaten Buleleng.

\subsubsection{Penilaian aksesibilitas dan fasilitas pendukung}

Penilaian aksesibilitas dan fasilitas pendukung merupakan penilaian yang digunakan untuk mengevaluasi faktor internal dari daya tarik wisata itu sendiri. Adapun yang dinilai meliputi kualitas aksesibilitas dan fasilitas penunjang daya tarik wisata (Table 6).

Tabel 4. Penilaian aksesibilitas dan fasilitas penunjang daya tarik wisata

\begin{tabular}{|c|c|c|c|c|c|c|c|c|c|}
\hline \multirow{3}{*}{ No } & \multirow{3}{*}{ Unit Lanskap Sejarah } & \multicolumn{8}{|c|}{ Komponen Penilaian } \\
\hline & & \multicolumn{3}{|c|}{ Aksesibilitas } & \multicolumn{3}{|c|}{ Fasilitas Penunjang Daya Tarik Wisata } & \multirow[t]{2}{*}{ Total } & \multirow{2}{*}{ Kategor } \\
\hline & & A & $\mathrm{B}$ & C & $\mathrm{D}$ & $E$ & $\mathrm{~F}$ & & \\
\hline 1 & $\begin{array}{l}\text { Daya tarik wisata Eks } \\
\text { Pelabuhan Buleleng }\end{array}$ & 3 & 2 & 2 & 3 & 2 & 3 & 15 & Tinggi \\
\hline
\end{tabular}

(Keterangan: Rendah: $6 \leq n \leq 10$; Sedang: $11 \leq n \leq 14$; Tinggi: $15 \leq n \leq 18$

A: waktu tempuh dari terminal terdekat, B: ketersediaan angkutan umum untuk menuju DTW, C: kondisi prasarana jalan menuju DTW, D: ketersediaan fasilitas kebutuhan fisik, E: ketersediaan fasilitas kebutuhan sosial, F: ketersediaan fasilitas pelengkap.)

Untuk penilaian aksesibilitas dan fasilitas penunjang daya tarik wisata di nilai secara keseluruhan atau satu kesatuan daya tarik wisata Eks Pelabuhan Buleleng. Hal ini dilakukan mengingat elemen penyusunnya sangat berdekatan dan berada pada lokasi yang sama.

\subsubsection{Analisis Faktor Eksternal}

a. Kebijakan pemerintah

Berdasarkan Peraturan Bupati Buleleng Nomor 51 Tahun 2017, Kabupaten Buleleng memiliki 86 daya tarik wisata yang tersebar di 9 kecamatan yang ada di Kabupaten Buleleng. Kecamatan Buleleng memiliki 9 daya tarik wisata yang layak untuk dikunjungi salah satunya merupakan Eks Pelabuhan Buleleng.

b. Ekonomi 
Pesatnya pertumbuhan kawasan pelabuhan buleleng pada masa pemerintahan Hindia Belanda memberikan pengaruh pada kawasan di sekitar pelabuhan yang mulai menjadi kawasan perdagangan. Deretan pertokoan bermunculan di kawasan ini, sebagai sarana jual-beli barang distribusi pelabuhan pada masa itu. Pertokoan ini sebagian besar dimiliki oleh kaum dari etnis Cina dan warga Kampung Bugis yang memang terkenal sebagai bangsa pedagang.

c. Sosial budaya

Kebudayaan yang terdapat di kawasan Eks Pelabuhan Buleleng ini sangat beragam. Ada kebudayaan Bali yang dibawa oleh masyarakat asli Buleleng yang bermukim di sekitar lokasi, ada kebudayaan Cina yang dibawa oleh para pedagang etnis Cina di Eks Pelabuhan Buleleng, dan kebudayaan Islam yang dibawa oleh masyarakat Kampung Bugis dan Kampung Kajanan. Eksistensi ketiga kebudayaan ini dibuktikan dengan adanya tempat ibadah dari masing-masing kebudayaan, yaitu Pura Segara Buleleng, Klenteng Lie Gwan Kiong, serta Masjid Agung Jami (Masjid tertua di Bali). Ketiga kebudayaan ini hidup berdampingan, dan saling bertoleransi.

d. Teknologi

Teknologi berperan penting dalam membantu menyebarkan informasi ke seluruh penjuru dunia. Dinas Pariwisata Kabupaten Buleleng dalam menarik wisatawan untuk datang ke Kabupaten Buleleng menggunakan media informasi berupa web site, pamphlet, brosur dan lain-lain.

\subsection{Tahap Perencanaan \\ 3.4.1 Konsep dasar}

Konsep dasar perencanaan lanskap yang akan dikembangkan pada tapak adalah pelestarian Eks Pelabuhan Buleleng dengan konsep wisata sejarah edukatif dan rekreatif yang mampu mendukung pelestarian sumberdaya sejarah pada tapak dengan menjadikan Eks Pelabuhan Buleleng sebagai pusat informasi sejarah dan kebudayaan serta rekreasi yang ada di Kabupaten Buleleng.

\subsubsection{Pengembangan Konsep}

Pengembangan konsep bertujuan untuk menjabarkan konsep dasar yang telah direncanakan sebelumnya. Pengembangan konsep yang dilakukan dibuat menjadi enam bagian yaitu konsep ruang, konsep sirkulasi, konsep vegetasi, konsep aktifitas, dan konsep fasilitas.

\subsubsection{Konsep Ruang}

Pembagian ruang dilakukan berdasarkan tujuan pengembangan tapak untuk wisata sejarah. Untuk itu dibentuklah ruang penerimaan, ruang wisata, dan ruang penyangga. Ruang penerimaan merupakan ruang yang pertama kali didatangi oleh pengunjung. Ruang ini berfungsi sebagai identitas atau ciri khusus sehingga menarik minat pengunjung. Ruang wisata adalah ruang tempat aktifitas wisata berlangsung. Ruang wisata terbagi menjadi ruang wisata utama dan ruang wisata pendukung.

\subsubsection{Konsep Sirkulasi}

Konsep sirkulasi berfungsi sebagai penghubung antar ruang dan dalam masing-masing ruang pada tapak. Sirkulasi dalam tapak terdiri dari sirkulasi primer dan sirkulasi sekunder. Sirkulasi primer akan menghubungkan setiap ruang yang ada pada tapak. Sirkulasi sekunder adalah sirkulasi yang menghubungkan sub-sub ruang dalam tapak (Gambar 3). Konsep sirkulasi pada tapak berorientasi kepada pejalan kaki.

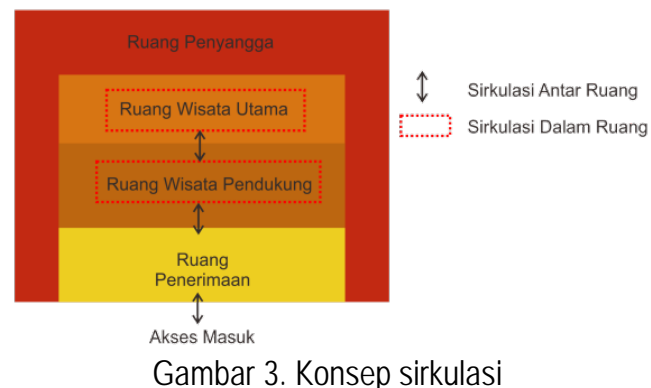




\subsubsection{Konsep Vegetasi}

Konsep vegetasi menjabarkan vegetasi yang akan digunakan pada tapak. Fungsi vegetasi yang digunakan pada tapak adalah fungsi estetik, pengarah, pembatas antar ruang, dan penaung.

\subsubsection{Perencanaan lanskap}

\subsubsection{Tata ruang}

Pada tahap konsep telah ditentukan ruang-ruang yang terbentuk dalam tapak beserta aktifitas dan fasilitasnya. Berdasarkan hasil perhitungan kebutuhan wisata dan upaya menjaga sumberdaya Eks Pelabuhan Buleleng, maka direncanakan penambahan luas sebesar $2.195 \mathrm{~m}^{2}$ pada batas tapak dibagian timur tepatnya berada di taman Soenda Ketjil yang merupakan Eks Terminal Kampung Tinggi. Penambahan luas ini dilakukan sebab luas eksisting tapak kurang memungkinkan untuk menampung aktifitas pendukung wisata yang akan dikembangkan pada tapak yaitu sebagai area parkir. Rencana blok membagi tapak menjadi 4 ruang utama yaitu ruang penerimaan, ruang pendukung wisata, ruang wisata utama, dan ruang penyangga.

Rencana ruang menjabarkan lebih lanjut dari konsep ruang yang telah dibuat sebelumnya. Pada konsep ruang terdapat $0,75 \%\left(888,03 \mathrm{~m}^{2}\right)$ ruang penerimaan, $22,9 \%\left(2705,05 \mathrm{~m}^{2}\right)$ ruang pendukung wisata, $66,505 \%\left(7854,5 \mathrm{~m}^{2}\right)$ ruang wisata utama dan $9,845 \%\left(1162,73 \mathrm{~m}^{2}\right)$ ruang penyangga.

\section{A. $\quad$ Ruang penerimaan}

Ruang penerimaan merupakan ruang yang pertama kali didatangi oleh pengunjung. Ruang penerimaan berfungsi sebagai identitas dan daya tarik pada tapak. Akses untuk masuk ke dalam tapak ditata ulang untuk memberikan unity dan mengakomodir pengunjung dari lahan parkir di timur tapak. Pada ruang ini dapat ditambahkan signage yang berfungsi memberi identitas pada tapak.

B. Ruang pendukung wisata

Ruang pendukung wisata merupakan ruang yang berfungsi untuk pelayanan kegiatan wisata pada tapak. Fasilitas penunjang wisata yang ada dalam tapak diantaranya kantor UPT. Pengelola daya tarik wisata Eks Pelabuhan Buleleng yang berfungsi bagi pengunjung untuk mendapatkan informasi awal mengenai Eks Pelabuhan Buleleng. Fasilitas lainnya pada ruang ini adalah ticket box, bangku taman, tempat parkir, kios souvenir, tempat makan, dan toilet. Pengembangan ruang pendukung wisata dilakukan pada area luar tapak yang mengalami perluasan untuk menampung fasilitas parkir yang tidak terakomodir pada tapak dan tidak menggangu kegiatan wisata dalam tapak.

C. Ruang wisata utama

Ruang wisata utama merupakan ruang yang dikembangkan sebagai daya tarik utama wisata sejarah pada tapak. Pengembangan yang dilakukan pada area wisata utama dibatasi untuk menjaga sumberdaya tapak. Pada area ini aktifitas yang dilakukan ditekankan pada aktifitas pengenalan sejarah melalui koleksi dan atraksi wisata yang berlangsung di dalamnya.

Ruang wisata utama sebagian besar memanfaatkan bangunan utama Eks Pelabuhan Buleleng dan area sekitarnya. Pemanfaatan bangunan pada Eks Pelabuhan Buleleng dibagi menjadi 5 sub ruang diantaranya sub ruang sejarah Kabupaten Buleleng, sub ruang kebudayaan, sub ruang sejarah Eks Pelabuhan Buleleng, sub ruang perpustakaan, dan sub ruang pertunjukan. Penjabaran masing-masing sub ruang adalah sebagai berikut:

1. Sub ruang sejarah Kabupaten Buleleng memanfaatkan bangunan Jembatan Kolonial, Tugu I Ketut Merta, dan Monumen Yudha Mandala Tama. Tiga elemen ini mewakili identitas Kabupeten Buleleng dan perjuangan rakyat Buleleng memperjuangkan kemerdekaan.

2. Sub ruang kebudayaan memanfaatkan bangunan Klenteng Ling Gwan Kiong dan Pura Segara Buleleng sebagai daya tarik wisatanya. Kedua bangunan ini digunakan karena mewakili akulturasi budaya yang terdapat pada tapak.

3. Sub ruang sejarah Eks Pelabuhan Buleleng memanfaatkan bangunan museum Soenda Ketjil dan Eks Dermaga Pelabuhan Buleleng. Bangunan ini mewakili Eks Pelabuhan Buleleng tempo dulu.

4. Sub ruang perpustakaan memanfaatkan bangunan yang berada di belakang Museum Soenda Ketjil.

5. Sub ruang pertunjukan memanfaatkan Gedung I Gusti Ketut Pudja.

D. Ruang penyangga

Ruang penyangga merupakan ruang dengan intensitas dan kesesuaian wisata yang rendah. Banyaknya aktifitas wisata yang dilakukan pada ruang ini cukup terbatas. Area ini lebih difungsikan untuk menjaga sumberdaya tapak. Tujuan utama pengembangan ruang ini adalah untuk menjaga kondisi tapak agar 
keberadaan obyek berupa benda cagar budaya tidak mengalami kerusakan. Luas area ini adalah 1162,73 $(9,845 \%)$. Penataan pada area ini dilakukan dengan penambahan vegetasi, perkerasan berupa pemecah ombak dan senderan.

\subsubsection{Tata Sirkulasi}

Sirkulasi yang dikembangkan dalam tapak terbagi menjadi sirkulasi primer dan juga sekunder. Sirkulasi primer menghubungkan ruang-ruang dalam tapak. Sedangkan sirkulasi sekunder merupakan jalur sirkulasi yang menghubungkan setiap elemen dalam ruang. Pengaturan sirkulasi pengunjung dibedakan menjadi tiga yaitu sirkulasi pemedek, pengunjung dan kendaraan. Pembedaan jalur ini dilakukan agar tidak saling mengganggu aktivitas masing-masing.

\subsubsection{Tata Vegetasi}

Jenis vegetasi pada theme garden disesuaikan untuk memperkuat estetika dan karakter tapak. Karakter pada chinease contemporary garden dibuat untuk memperkuat identitas klenteng. Jenis vegetasi yang digunakan seperti rumput jepang, kucai, tanaman bonsai, bambu, dan penambahan ornament seperti batu. Western contemporary garden dibuat untuk memperkuat karakter kolonial dalam tapak. Jenis vegetasi yang digunakan lebih banyak menggunakan jenis semak rendah dan tanaman bunga dengan warna cerah seperti tanaman pucuk merah, kembang kertas, dan tanaman berbunga dengan warna cerah. Balinese garden dibuat untuk memperkuat identitas sekitar Pura Segara Buleleng. Vegetasi yang digunakan kebanyakan tanaman lokal dengan warna yang dominan hijau dengan aksen warna merah, jingga, kuning, dan putih yang umumnya diperoleh dari bunga kembang sepatu atau kamboja sebagai identitas taman tradisional Bali.

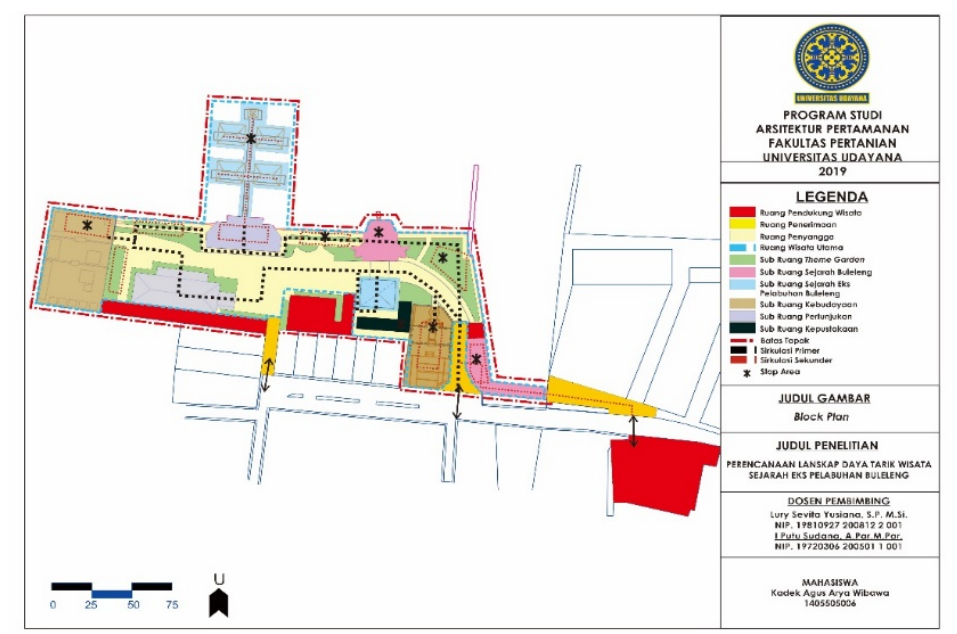

Gambar 4. Block Plan

\subsubsection{Rencana ruang, aktivitas, dan fasilitas}

Rencana antara ruang, aktifitas, dan fasilitas menggambarkan kegiatan serta fasilitas yang diperlukan dalam ruang yang sudah di tentukan sebelumnya. Rencana antara ruang, aktifitas, dan fasilitas dapat dilihat pada Tabel 7.

Tabel 7. Rencana ruang, aktivitas, dan fasilitas

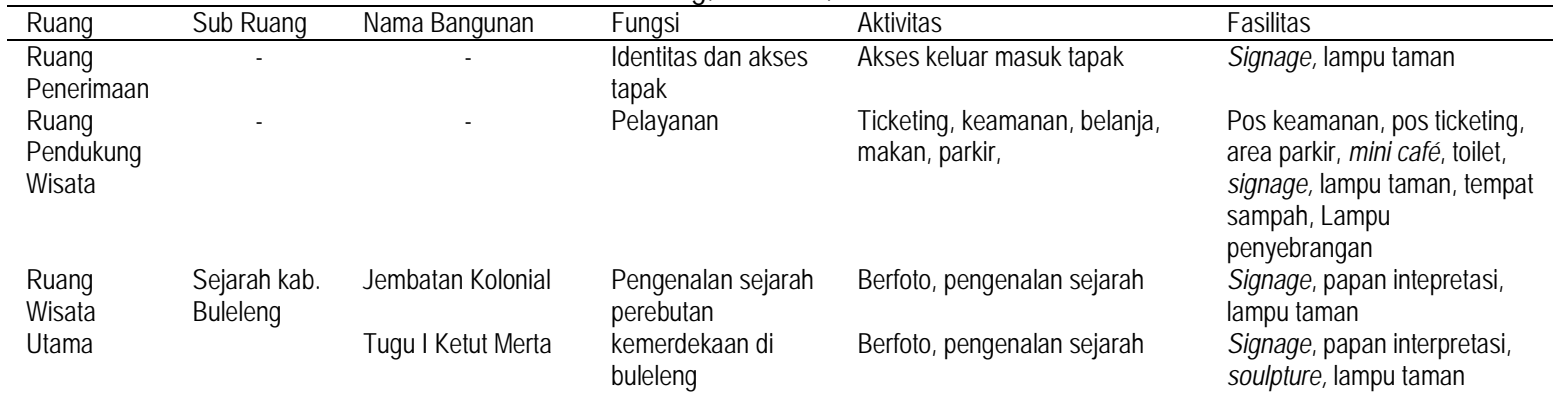




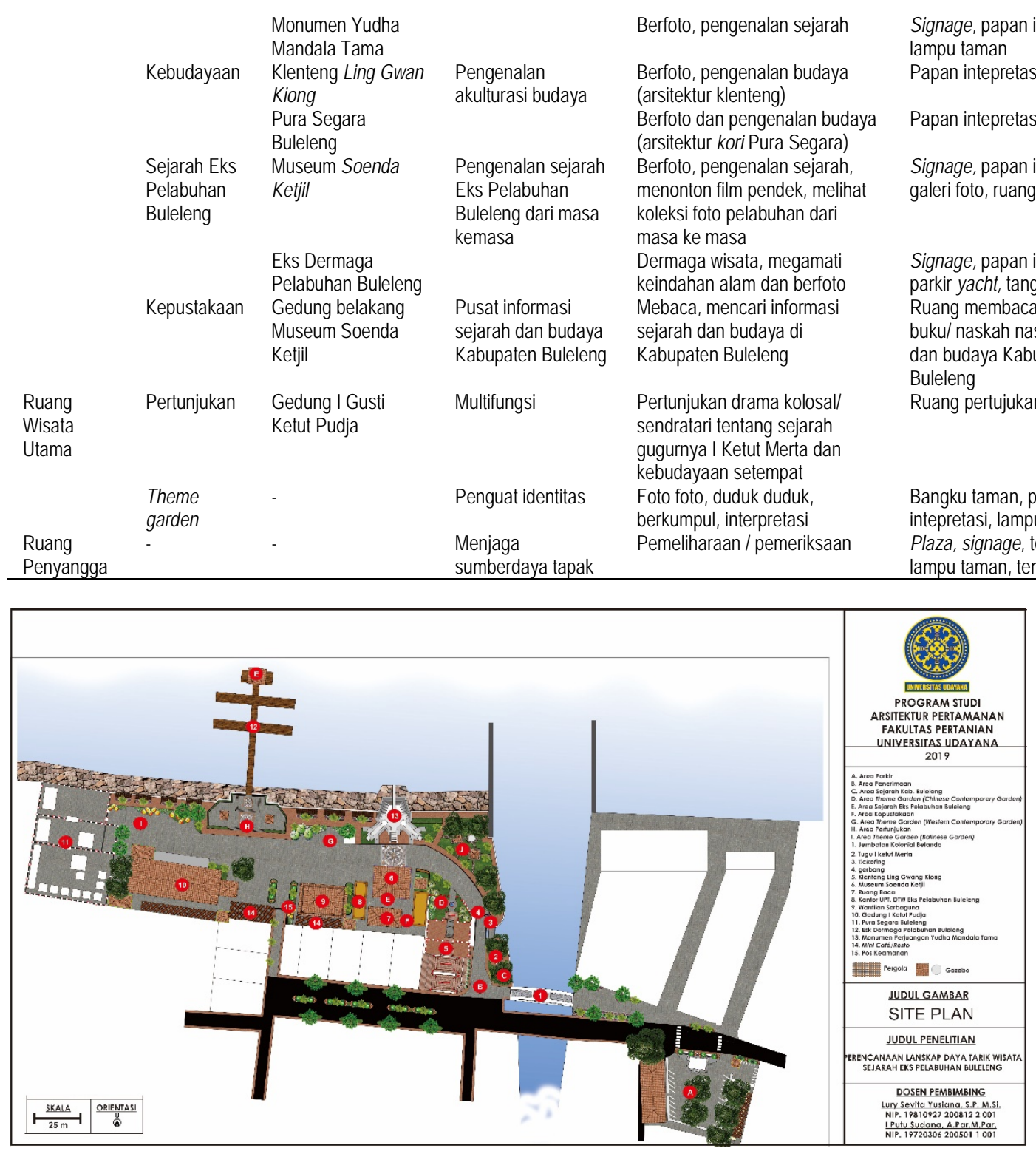

Gambar 5. Site Plan

\section{Simpulan}

Eks Pelabuhan Buleleng memiliki potensi yang sangat besar untuk direncanakan sebagai daya tarik wisata sejarah karena kearifan lokal yang ada di sekitar tapak serta nilai sejarah yang ada mulai dari zaman kerajaan, zaman kolonial, sampai perjuangan pemuda Buleleng dalam merebut kemerdekaan. Selain potensi nilai edukasi sejarah dan kearifan budaya lokal, dalam perencanaannya banyak dijumpai kendala pada tapak. Kendala yang ditemui seperti tema dan konsep perencanaan yang kurang tertata, sirkulasi yang kurang jelas pada tapak, pemanfaatan lahan yang belum optimal, masalah sampah, dan lain-lain.

Bedasarkan potensi dan kendala yang ditemui di lapangan maka dirumuskanlah konsep perencanaan lanskap daya tarik wisata sejarah Eks Pelabuhan Buleleng. Konsep dasar perencanaan lanskap yang akan dikembangkan pada tapak adalah pelestarian Eks Pelabuhan Buleleng dengan konsep wisata sejarah edukatif dan rekreatif yang mampu mendukung pelestarian sumberdaya sejarah pada tapak dengan menjadikan Eks Pelabuhan Buleleng sebagai pusat informasi sejarah dan kebudayaan serta rekreasi yang ada di Kabupaten Buleleng Pendekatan yang digunakan dalam penerapan konsep adalah pendekatan aktivitas yang terdiri atas konsep ruang wisata, aksesibilitas dan sirkulasi, fasilitas wisata, dan aktivitas wisata, serta pendekatan sumber daya yang meliputi elemen fisik dan nonfisik. 


\section{Daftar pustaka}

Badan Meteorologi, Klimatologi, dan Geofisika (BMKG) Wilayah III Denpasar. 2018. Data curah hujan Kabupaten Buleleng Pos Sukasada Tahun 2008 sampai 2017. Denpasar (ID): BMKG Wilayah III Denpasar.

Badan Pusat Statistik. Statistik Daerah Kabupaten Buleleng Tahun 2011. Kabupaten Buleleng (ID).

Google Inc. 2016. Google Maps: Peta Lokasi Eks Pelabuhan Buleleng. http://maps.google.com/ (Diakses 10 Mei 2017 pukul. 10.30 wita)

Harris C. W, Dines N. T. 1988. Time Saver Standards for Landscape Architecture. New York (US): The McGraw-Hill Companies, Inc.

Wijaya, Putu Tastra. 2016. Pesona Wisata Indonesia: Objek Wisata Sejarah di Kabupaten Buleleng. UPT Daya tarik Wisata. UPT Pengelola Daya tarik Wisata Eks Pelabuhan Buleleng. Singaraja 